Campos Neutrais - Revista Latino-Americana de Relações Internacionais Vol. 2, $\mathrm{N}^{\mathrm{O}}$ 2, Maio-agosto de 2020. Santa Vitória do Palmar - RS.

\title{
A proteção do consumidor na União Europeia com a formação de um mercado único digital
}

\author{
Laís Bergstein* \\ Felipe Kirchner**
}

\begin{abstract}
Resumo: O presente trabalho trata da política de defesa do consumidor na União Europeia, dos seus primórdios até a edição de uma agenda do consumidor para incentivar a confiança e o crescimento do mercado europeu. São analisadas as Diretivas sobre a proteção do consumidor, especialmente, a relativa a determinados aspectos dos contratos de utilização periódica de bens, de aquisição de produtos de férias de longa duração, de revenda e de troca dos contratos de timesharing. Apresentam-se as recentes propostas da Comissão Europeia sobre certos aspetos relativos aos contratos de fornecimento de conteúdos digitais e sobre alguns aspectos dos contratos de vendas de bens on-line ou à distância. Conclui-se pela conveniência de consolidação do conteúdo das duas propostas em um único documento e pela possibilidade de importação de algumas das regras para inserção no ordenamento jurídico brasileiro.
\end{abstract}

Palavras-chave: Direito da União. Mercado Único Digital. Conteúdos Digitais. Vendas online.

\section{Consumer protection in the european union with a single digital market}

\begin{abstract}
The present work deals with consumer policy in the European Union from its beginnings until the edition of a consumer agenda to encourage the growth of confidence in the European market. It analyses the Consumer Protection Directives, specially the one related to certain aspects of contracts for the periodic use of goods, the purchase of long-term holiday products, resale and exchange: the time-sharing contracts. Subsequently, it introduces the European Commission's recent proposals on certain aspects of contracts for the provision of digital content and on some aspects of online or distance selling contracts for goods. Finally, it concludes that it would be convenient to consolidate the content of the two proposals in a single document and that some of the rules proposed should be inserted into the Brazilian legal system.
\end{abstract}

Keywords: European Union law. Digital Single Market. Digital Contents. Online sales.

\section{Considerações iniciais}

A União Europeia destaca-se como uma organização internacional peculiar em comparação com outras organizações desse tipo. Isso porque ela atende não apenas aos requisitos de uma organização internacional constituída, basicamente, por um tratado entre Estados (com personalidade jurídica própria, objetivos, órgãos, sede etc.), mas também aos requisitos de uma organização supranacional. As normas por ela concebidas vinculam, jurídica e diretamente, os residentes nos Estados-membros, sem necessidade de um ato específico do legislador nacional que transforme e incorpore esse direito ao direito interno

\footnotetext{
${ }^{*}$ Doutoranda em Direito do Consumidor e Concorrencial pela Universidade Federal do Rio Grande do Sul (UFRGS). Mestre em Direito Econômico e Socioambiental pela Pontifícia Universidade Católica do Paraná (PUC/PR). Coordenadora Acadêmica da Especialização em Direito do Consumidor e Direitos Fundamentais da UFRGS. Membro do Grupo de Pesquisa Mercosul, Direito do Consumidor e Globalização da UFRGS e do Grupo de Pesquisa Virada de Copérnico da Universidade Federal do Paraná (UFPR). Advogada. lais@dotti.adv.br

*** Mestre em Direito Privado pela Universidade Federal do Rio Grande do Sul (UFRGS). Professor na Pontifícia Universidade Católica do Rio Grande do Sul (PUCRS). Defensor Público no Estado do RS, atuando perante a $3^{\text {a }}$ Defensoria Pública de Direitos Humanos, na Direção do Núcleo de Defesa do Consumidor e de Tutelas Coletivas (NUDECONTU) e na Coordenação da Revista da Defensoria Pública. felipekirchner@gmail.com
} 
Campos Neutrais - Revista Latino-Americana de Relações Internacionais Vol. 2, $\mathrm{N}^{\mathrm{O}}$ 2, Maio-agosto de 2020. Santa Vitória do Palmar - RS.

de cada um deles. ${ }^{1}$

Trata-se de organização inovadora e precursora que, nas palavras de Jean Monnet, não possui um fim em si mesma, "é um processo de transformação que continua o de que nossas formas de vida nacionais provieram no decorrer de uma fase anterior da História. [...] As nações soberanas do passado não são mais o quadro em que podem resolver os problemas do presente." ${ }^{2}$ Visando, justamente, atingir as dimensões necessárias ao seu progresso, a Comissão Europeia inovou, mais uma vez, ao estabelecer como uma das suas prioridades-chave, a criação de um "Mercado Único Digital” (Digital Single Market).

Os avanços observados, no âmbito do Direito da União Europeia, são fonte de inspiração, também, para o ordenamento jurídico brasileiro. Os temas lá debatidos, também, são latentes no nosso território, o que motiva sua análise de modo detido. A partir da observação experiência da União Europeia, que possui um dos sistemas de defesa do consumidor mais avançados do mundo, é possível extrair algumas lições para o direito brasileiro.

O presente trabalho trata, inicialmente, da política de defesa do consumidor na União Europeia, dos seus primórdios até a edição de uma agenda do consumidor para incentivar a confiança e o crescimento do mercado europeu. Em um primeiro momento, analisam-se alguns dos mais relevantes impactos da Diretiva relativa a contratos de timesharing na União Europeia. Apresentam-se, na sequência, as recentes propostas da Comissão Europeia sobre certos aspetos relativos aos contratos de fornecimento de conteúdos digitais e sobre alguns aspectos dos contratos de vendas on-line ou à distância de bens. São indicadas, enfim, algumas considerações acerca da conveniência de consolidação das duas propostas em um único documento.

\section{A política de defesa do consumidor na união europeia}

\subsection{Primórdios da proteção do consumidor na União Europeia}

Em 1973, a Comissão das Nações Unidas sobre os Direitos do Homem deliberou que o consumidor deveria gozar de quatro direitos fundamentais: 1) o direito à segurança; 2) o direito à informação sobre produtos, serviços e suas condições de venda; 3 ) o direito à escolha de bens alternativos de qualidade satisfatória a preços razoáveis; e 4) o direito de

${ }^{1}$ RECHSTEINER, Beat Walter. Direito Internacional Privado: teoria e prática. 12. ed. São Paulo: Saraiva, 2009. p. 70-71.

${ }^{2}$ MONNET, Jean. Memórias: a construção da unidade europeia(1976).Tradução: Ana Maria Falcão. Brasília: Editora Universidade de Brasília, 1986. p. 460-461. 
Campos Neutrais - Revista Latino-Americana de Relações Internacionais Vol. 2, $\mathrm{N}^{\mathrm{O}}$ 2, Maio-agosto de 2020. Santa Vitória do Palmar - RS.

ser ouvido no processo de decisão governamental. Ainda em 1973, a Assembleia Consultiva da Comunidade Europeia aprovou a Resolução 543, que deu origem à Carta Europeia de Proteção ao Consumidor.

Daí por diante, um número crescente de países operou a aprovação de legislação de proteção aos direitos do consumidor. ${ }^{3}$ A partir de1992, com o Tratado da União Europeia (Maastricht $)^{4}$, as medidas de tutela dos direitos dos consumidores passaram a fundar-se em uma base jurídica independente, uma vez que o art. 129-A, do Tratado, concedeu a este tema o posto de política comunitária. Com o Tratado de Amsterdam ${ }^{5}$, em 1997, a lista de direitos dos consumidores foi incrementada. ${ }^{6}$

A Carta dos Direitos Fundamentais da União Europeia, tal como incorporada nos Tratados pelo artigo $6^{\circ}$, do Tratado da União Europeia (TUE), estabelece que "as políticas da União devem assegurar um elevado nível de defesa dos consumidores." ${ }^{77}$ Entende-se que, em uma economia eficiente e integrada em um mercado único, o consumidor deve ter a garantia de que os seus direitos serão defendidos em caso de problemas decorrentes da compra bens ou da contratação de serviços em outros países da União Europeia. Para a sua proteção, estima-se um custo anual de 5 (cinco) cents por pessoa. ${ }^{8}$

Seguindo esta premissa, uma vez que a defesa dos consumidores consta no rol de competências partilhadas entre a União e os Estados-membros (art. $4^{\circ}, 2$, f, TFUE), o Tratado sobre o Funcionamento da União Europeia - TFUE dispõe sobre a defesa dos consumidores no Título XV, artigo $169 .^{9}$

O Tratado estabelece que "a fim de promover os interesses dos consumidores e assegurar um elevado nível de defesa destes, a União contribuirá para a proteção da saúde,

\footnotetext{
${ }^{3}$ MIRAGEM, Bruno. A defesa administrativa do consumidor no Brasil. São Paulo, Revista de Direito do Consumidor, v. 46, Abr./Jun., 2003. p. 120-164.

${ }^{4}$ UNIÃO EUROPEIA. Tratado da União Europeia (Maastricht, 1992). Disponível em: <https://europa.eu/european-union/sites/europaeu/files/docs/body/treaty_on_european_union_pt.pdf> Acesso em: 15 out. 2019.

${ }^{5}$ UNIÃO EUROPEIA. Tratado de Amsterdam (outubro de 1997). Disponível em: <https://europa.eu/european-union/sites/europaeu/files/docs/body/treaty_of_amsterdam_pt.pdf> Acesso em: 15 out. 2019.

${ }^{6}$ DURÁ, Rafael Marimón. La protección de los consumidores en el derecho comunitario europeo. In: PIMENTEL, Luiz Otávio; MOTA, Carlos Esplugues; BARRAL, Welber. Direito Internacional Privado: União Europeia e Mercosul. Florianópolis: Fundação Boiteux, 2007. p. 96.

${ }^{7}$ UNIÃO EUROPEIA. Carta dos Direitos Fundamentais da União Europeia. Disponível em: $<$ https://europa.eu/european-union/sites/europaeu/files/eu_citizenship/consolidatedtreaties_pt.pdf\#page=125> Acesso em: 15 out. 2019.

${ }^{8}$ UNIÃO EUROPEIA. A UE por temas: consumidores. Disponível em: <https://europa.eu/europeanunion/topics/consumers_pt> Acesso em: 15 out. 2019.

${ }^{9}$ UNIÃO EUROPEIA. Tratado sobre o Funcionamento da União Europeia - TFUE. Disponível em: $<$ https://europa.eu/european-union/sites/europaeu/files/eu_citizenship/consolidatedtreaties_pt.pdf\#page=125> Acesso em: 15 out. 2019.
} 
Campos Neutrais - Revista Latino-Americana de Relações Internacionais Vol. 2, $\mathrm{N}^{\mathrm{O}}$ 2, Maio-agosto de 2020. Santa Vitória do Palmar - RS.

da segurança e dos interesses econômicos dos consumidores, bem como para a promoção do seu direito à informação, à educação e à organização para a defesa dos seus interesses." As medidas adotadas, no âmbito da União Europeia, não obstam que os Estados-membros mantenham ou introduzam medidas de proteção ainda mais estritas, ou seja, mais favoráveis aos consumidores, mas desde que sejam compatíveis com os Tratados e notificadas à Comissão.

$\mathrm{O}$ artigo $26^{\circ}, \mathrm{n}^{\circ} 2$, do TFUE, estabelece que "o mercado interno compreende um espaço sem fronteiras internas no qual a livre circulação das mercadorias, das pessoas, dos serviços e dos capitais é assegurada de acordo com as disposições dos Tratados."10

A proteção aos consumidores, na União Europeia, é assegurada, atualmente, no âmbito do Parlamento (pela Comissão do Ambiente, da Saúde Pública e da Segurança Alimentar e pela Comissão do Mercado Interno e da Proteção dos Consumidores), do Conselho da União Europeia (pelo Conselho Emprego, Política Social, Saúde e Consumidores - EPSCO), da Comissão (de Consumidores e de Saúde e Segurança Alimentar), do Comitê Econômico e Social Europeu (pela Secção do Emprego, Assuntos Sociais e Cidadania), do Comitê das Regiões (pela Comissão dos Recursos Naturais NAT) e, por fim, por meio das Agências da União Europeia (especialmente a CHAFEA e a Autoridade Europeia para a Segurança dos Alimentos). ${ }^{11}$

Outrossim, o Regulamento da UE relativo à cooperação no domínio da defesa do consumidor (Regulamento (CE) no 2006/2004) cria uma rede de autoridades competentes para controlar a aplicação da legislação relativa à defesa do consumidor. Cada Estadomembro da União designa, para integrar a rede de assistência mútua, as autoridades públicas responsáveis pela aplicação da legislação de defesa do consumidor. Todos os países dispõem de um serviço de ligação único que assegura a coordenação entre as autoridades nacionais. Graças a esta rede, uma autoridade nacional de um país da União pode solicitar a uma sua congênere de outro Estado-membro que intervenha em casos de infração transfronteiriça às regras europeias. A cooperação abrange as regras de defesa dos

\footnotetext{
10 “TÍTULO I. O MERCADO INTERNO. Artigo 26․ 1. A União adopta as medidas destinadas a estabelecer o mercado interno ou a assegurar o seu funcionamento, em conformidade com as disposições pertinentes dos Tratados. 2. O mercado interno compreende um espaço sem fronteiras internas no qual a livre circulação das mercadorias, das pessoas, dos serviços e dos capitais é assegurada de acordo com as disposições dos Tratados. 3. O Conselho, sob proposta da Comissão, definirá as orientações e condições necessárias para assegurar um progresso equilibrado no conjunto dos sectores abrangidos.” (UNIÃO EUROPEIA. Tratado sobre o Funcionamento da União Europeia - TFUE. Disponível em: <https://europa.eu/europeanunion/sites/europaeu/files/eu_citizenship/consolidated-treaties_pt.pdf\#page=125> Acesso em: 15 out. 2019.) ${ }^{11}$ UNIÃO EUROPEIA A UE por temas: consumidores. Disponível em: <https://europa.eu/europeanunion/topics/consumers_pt> Acesso em: 15 out. 2019.
} 
Campos Neutrais - Revista Latino-Americana de Relações Internacionais Vol. 2, $\mathrm{N}^{\mathrm{O}}$ 2, Maio-agosto de 2020. Santa Vitória do Palmar - RS.

consumidores em vários domínios, como, por exemplo, a diretiva relativa às práticas comerciais desleais ou a diretiva relativa às cláusulas contratuais abusivas. ${ }^{12}$

A despeito do grande avanço europeu na proteção ao consumidor, é natural que existam alguns projetos que, até o momento, não deram certo. Cita-se, exemplificativamente, a proposta de uma política comum de referência em Direito Privado (Draft Common Framework of Reference - DCFR) ${ }^{13}$, a de elaboração de um Código Civil Europeu $^{14}$, a de uma diretiva mais abrangente de proteção dos direitos dos consumidores e a proposta de um Regulamento relativo a um direito europeu comum da compra e venda. ${ }^{15}$

A bem da verdade, no caso do Direito do Consumidor na União Europeia, não se pode falar, exatamente, em um sistema integrado, complexo e sistemático de normas jurídicas, mas de um conjunto de disposições descoordenadas entre si, que regulam aspectos parciais da tutela do consumidor em suas diversas facetas. ${ }^{16}$

\subsection{A agenda do consumidor para incentivar a confiança e o crescimento do mercado europeu}

As principais Diretivas da União Europeia que, hoje, integram a agenda de consolidação de direitos do consumidor europeu são as seguintes: Diretiva 93/13/CEE, Diretiva 1999/44/CE, Diretiva 1995/46/CE, Diretiva 2002/58/CE, 2005/29/CE, Diretiva 2009/22/CE, 2011/83/EU e Diretiva 2013/11/EU.

A Diretiva 93/13/CEE do Conselho, de 5 de abril de 1993, relativa às cláusulas abusivas nos contratos celebrados com os consumidores, define que uma cláusula contratual que não tenha sido objeto de negociação individual é considerada abusiva quando, a despeito da exigência de boa-fé, der origem a um desequilíbrio significativo em detrimento do consumidor, entre os direitos e obrigações das partes decorrentes do

\footnotetext{
${ }^{12}$ UNIÃO EUROPEIA. Regulamento (UE) no 2006/2004, do Parlamento Europeu e do Conselho, de 27 de outubro de 2004, relativo à cooperação entre as autoridades nacionais responsáveis pela aplicação da legislação de defesa do consumidor. <http://eur-lex.europa.eu/legalcontent/PT/TXT/HTML/?uri=URISERV:132047\&from=EN> Acesso em: 15 out. 2019.

${ }^{13}$ VON BAR, Christian; CLIVE, Eric; SCHULTE-NÖLKE, Hans. Principles, Definitions and Model Rules of European Private Law Draft Common Frame of Reference (DCFR). Disponível em:

<http://ec.europa.eu/justice/policies/civil/docs/dcfr_outline_edition_en.pdf> Acesso em: 15 out. 2019.

${ }^{14}$ Solicitado em 1989 pelo Parlamento Europeu. Official Journal of the European Communities, 1989, N. C $158 / 400$.

${ }^{15}$ UNIÃO EUROPEIA. Proposta de Regulamento do Parlamento Europeu e do Conselho relativo a um direito europeu comum da compra e venda (COM/2011/0635 final - 2011/0284 (COD). Disponível em: <http://eurlex.europa.eu/legal-content/PT/TXT/HTML/?uri=CELEX:52011PC0635\&from=EN>Acesso em: 15 out. 2019.

${ }^{16}$ DURÁ, Rafael Marimón. La protección de los consumidores en el derecho comunitario europeo. In: PIMENTEL, Luiz Otávio; MOTA, Carlos Esplugues; BARRAL, Welber. Direito Internacional Privado: União Europeia e Mercosul. Florianópolis: Fundação Boiteux, 2007. p. 95.
} 
Campos Neutrais - Revista Latino-Americana de Relações Internacionais Vol. 2, $\mathrm{N}^{\mathrm{O}}$ 2, Maio-agosto de 2020. Santa Vitória do Palmar - RS.

contrato. ${ }^{17}$ Além disso, ela obriga que os fornecedores informem aos consumidores a existência da garantia legal e, também, todas as condições para fazer uso da garantia comercial. $^{18}$

A Diretiva 1999/44/CE, do Parlamento Europeu e do Conselho, de 25 de maio de 1999, relativa a certos aspectos da venda de bens de consumo e das garantias a ela relativas, dispõe sobre o direito de regresso do vendedor que é responsabilizado perante o consumidor pela falta de conformidade resultante de um ato ou omissão do produtor, de um vendedor anterior da mesma cadeia contratual, ou de qualquer outro intermediário, o vendedor final. O responsável ou os responsáveis contra quem o vendedor final tem direito de regresso bem como as correspondentes ações e condições de exercício são determinados pela legislação nacional. ${ }^{19}$

A proteção dos indivíduos no que se refere ao tratamento dos dados pessoais é regida pela Diretiva 1995/46/CE, do Parlamento Europeu e do Conselho, de 24 de outubro de 1995 (relativa à proteção das pessoas singulares no que diz respeito ao tratamento de dados pessoais e à livre circulação desses dados) ${ }^{20}$ e pela Diretiva 2002/58/CE, do Parlamento Europeu e do Conselho, de 12 de julho de 2002, relativa ao tratamento de dados pessoais e à proteção da privacidade no setor das comunicações eletrônicas. ${ }^{21}$ Tais Diretivas, interessante destacar, são plenamente aplicáveis ao fornecimento de conteúdos digitais.

A Diretiva 2005/29/CE, do Parlamento Europeu e do Conselho, de 11 de maio de 2005, relativa às práticas comerciais desleais das empresas face aos consumidores no mercado interno, proíbe as práticas comerciais desleais. Entende-se como práticas desleais todas aquelas que sejam contrárias às exigências relativas à diligência profissional ou que distorçam ou sejam suscetíveis de distorcer, de maneira substancial, o comportamento econômico, em relação a um produto, do consumidor médio a que se destina ou que afeta,

\footnotetext{
${ }^{17}$ UNIÃO EUROPEIA. Directiva 93/13/CEE do Conselho, de 5 de Abril de 1993, relativa às cláusulas abusivas nos contratos celebrados com os consumidores. Disponível em: <http://eur-lex.europa.eu/legalcontent/PT/TXT/HTML/?uri=CELEX:31993L0013\&from=en> Acesso em: 15 out. 2019.

${ }^{18}$ DJUROVIC, Mateja. The Apple Case Today: Factual and Legal Assessment. Disponível em: <http://papers.ssrn.com/sol3/papers.cfm?abstract_id=2736380> Acesso em: 15 out. 2019.

${ }^{19}$ UNIÃO EUROPEIA. Diretiva 1999/44/CE do Parlamento Europeu e do Conselho, de 25 de maio de 1999, relativa a certos aspectos da venda de bens de consumo e das garantias a ela relativas. Disponível em: $<$ http://eur-lex.europa.eu/legal-content/PT/TXT/HTML/?uri=CELEX:31999L0044\&from=GA> Acesso em: 15 out. 2019.

${ }^{20}$ UNIÃO EUROPEIA. Diretiva 1995/46/CE do Parlamento Europeu e do Conselho. Disponível em: <http://eur-lex.europa.eu/legal-content/pt/TXT/?uri=CELEX\%3A31995L0046> Acesso em: 15 out. 2019.

${ }^{21}$ UNIÃO EUROPEIA. Diretiva 2002/58/CE do Parlamento Europeu e do Conselho, de 12 de julho de 2002, relativa ao tratamento de dados pessoais e à proteção da privacidade no setor das comunicações eletrônicas. Disponível em: 〈http://eur-lex.europa.eu/legal-content/PT/TXT/HTML/?uri=URISERV:124120\&from=PT> Acesso em: 15 out. 2019.
} 
Campos Neutrais - Revista Latino-Americana de Relações Internacionais Vol. 2, $\mathrm{N}^{\mathrm{O}}$ 2, Maio-agosto de 2020. Santa Vitória do Palmar - RS.

ou do membro médio de um grupo quando a prática comercial for destinada a um determinado grupo de consumidores. Em especial, são desleais as práticas comerciais enganosas ou agressivas. ${ }^{22}$

Posteriormente, a Diretiva 2011/83/EU, do Parlamento Europeu e do Conselho, de 25 de outubro de 201175, contribuiu com a aproximação de certos aspectos das disposições legislativas, regulamentares e administrativas dos Estados-membros relativas aos contratos celebrados entre consumidores e profissionais. Nos termos dessa Diretiva, é considerado consumidor "qualquer pessoa singular que, nos contratos abrangidos pela presente diretiva, atue com fins que não se incluam no âmbito da sua atividade comercial, industrial, artesanal ou profissional." ${ }^{23}$ Esse conceito de consumidor - ou seja, o não profissional - se aproxima à concepção delineada no Brasil pela teoria finalista.

Essa nova orientação, ao estabelecer um nível máximo de proteção do consumidor em todos os países, acabou por atingir e modificar várias Diretivas anteriores. Claudia Lima Marques afirma que a polêmica proposta inicial, de 2008, objetivava reformar as diretivas sobre proteção do consumidor e uni-las em um único texto obrigatório para os Estados, como se fosse um Código Europeu do Consumo. A doutrina e a prática foram contra esta unificação, e os Estados preferiram apostar no regime "opcional” do CFR (Common Frame of Reference ou Quadro-Comum de Referência), que, por sua voluntariedade, realizam uma unificação do direito do consumidor nacional de "baixo para cima". 24

Tem-se, ainda, a Diretiva 2013/11/EU, do Parlamento Europeu e do Conselho, de 21 de maio de 2013, sobre a Resolução alternativa de litígios de consumo ${ }^{25}$, bem como a Diretiva 2009/22/CE do Parlamento Europeu e do Conselho, de 23 de abril de 2009, que discrimina as ações inibitórias em matéria de proteção dos interesses dos consumidores. ${ }^{26}$

\footnotetext{
${ }^{22}$ UNIÃO EUROPEIA. Diretiva 2005/29/CE do Parlamento Europeu e do Conselho, de 11 de Maio de 2005, relativa às práticas comerciais desleais das empresas face aos consumidores no mercado interno. <http://eurlex.europa.eu/legal-content/PT/TXT/HTML/?uri=CELEX:32005L0029\&from=EM> Acesso em: 15 out. 2019.

${ }^{23}$ UNIÃO EUROPEIA. Diretiva 2011/83/UE do Parlamento Europeu e do Conselho, de 25 de outubro de 2011, relativa aos direitos dos consumidores. Disponível em: <http://eur-lex.europa.eu/legalcontent/PT/TXT/HTML/?uri=CELEX:32011L0083\&from=GA> Acesso em:15 out. 2019.

${ }^{24}$ BENJAMIN, Antonio Herman; MARQUES, Claudia Lima. Extrato do Relatório-Geral da Comissão de Juristas do Senado Federal para atualização do Código de Defesa do Consumidor (14.03.2012). São Paulo, Revista de Direito do Consumidor, v. 92, Mar./Abr., 2014. p. 303-365.

${ }^{25}$ UNIÃO EUROPEIA. Diretiva 2013/11/UE do Parlamento Europeu e do Conselho, de 21 de maio de 2013, sobre a resolução alternativa de litígios de consumo. Disponível em: <http://eur-lex.europa.eu/legalcontent/PT/TXT/HTML/?uri=CELEX:32013L0011\&from=em> Acesso em: 15 out. 2019.

${ }^{26}$ UNIÃO EUROPEIA. Diretiva 2009/22/CE do Parlamento Europeu e do Conselho, de 23 de Abril de 2009, relativa às ações inibitórias em matéria de proteção dos interesses dos consumidores. Disponível em: <http://eurlex.europa.eu/legal-content/PT/TXT/HTML/?uri=CELEX:32009L0022\&from=EN > Acesso em: 15 out. 2019.
} 
Campos Neutrais - Revista Latino-Americana de Relações Internacionais Vol. 2, $\mathrm{N}^{\mathrm{O}}$ 2, Maio-agosto de 2020. Santa Vitória do Palmar - RS.

A agenda do consumidor europeu, ou seja, o programa de defesa do consumidor da União Europeia para os anos de 2014 a 2020 faz respeitar a legislação, neste domínio, em todo o mercado comum, buscando conferir ao consumidor um elevado nível de proteção jurídica. O chamado Programa plurianual Consumidores da União Europeia (2014-2020), instituído por meio do Regulamento (UE) $n^{0}$ 254/2014, visa conferir-lhes mais poder através da informação e da educação.

O programa tem quatro objetivos principais: 1) consolidar e reforçar a segurança dos produtos por meio da adoção de sistemas eficazes de fiscalização do mercado ${ }^{27}$. Compreende-se que a segurança dos produtos é importante para os consumidores e para os fornecedores, a fim de assegurar uma concorrência saudável e leal; 2) informar e educar os consumidores e apoiar as organizações de consumidores; 3) assegurar o respeito aos direitos dos consumidores e garantir que possam buscar a reparação de danos de maneiras eficientes, rápidas e econômicas; 4) aumentar a eficácia da aplicação da legislação através do reforço da cooperação entre os organismos nacionais responsáveis pela aplicação da lei e da prestação de aconselhamento aos consumidores. ${ }^{28}$

Estudos comparativos são elaborados, no âmbito da União Europeia, para avaliar a implementação da proteção ao consumidor e, eventualmente, sugerir melhorias. Cita-se, exemplificativamente, o estudo sobre a forma de apresentação dos termos de garantia pela Apple em cada um dos contratos aplicados em diferentes países. ${ }^{29}$ Estudos desta natureza são uma importante forma de avançar, progressivamente, para a harmonização da proteção ao consumidor.

Não se ignoramos problemas constatados pelo legislador nacional relacionados à transposição incompleta ou incorreta de regras do Direito da União para o plano interno ${ }^{30}$, mas esses são, em síntese, os caminhos já trilhados e que conduziram à busca pela consolidação, também, de um mercado único digital.

\footnotetext{
${ }^{27}$ Cita-se, exemplificativamente, o sistema de alerta rápido da União Europeia para produtos de consumo perigosos - RAPEX.

${ }^{28}$ UNIÃO EUROPEIA. Regulamento (UE) no 254/2014 do Parlamento Europeu e do Conselho, de 26 de fevereiro de 2014, relativo a um programa plurianual "consumidores" para o período 2014-2020 e que revoga a Decisão $\quad \mathrm{n}^{\circ} \quad 1926 / 2006 / \mathrm{CE}$. <http://eur-lex.europa.eu/legalcontent/PT/TXT/HTML/?uri=CELEX:32014R0254\&from=PT> Acesso em: 15 out. 2019.

${ }^{29}$ DJUROVIC, Mateja. The Apple Case Today: Factual and Legal Assessment. Disponível em: <http://papers.ssrn.com/sol3/papers.cfm?abstract_id=2736380> Acesso em: 15 out. 2019.

${ }^{30}$ Sobre esse tema: MOSCONI, Franco. Diritto internazionale privato uniforme e disposizioni generali di diritto internazionale privato nazionale. In: MANSEL, Heinz-Peter; PFEIFFER, Thomas; KRONKE, Herbert; KRONKE, Christian; HAUSMANN, Rainer(org.) Festschrift für Erik Jayme. Band I. Munique: GmbH Publishers, 2004.p. 605-626.
} 
Campos Neutrais - Revista Latino-Americana de Relações Internacionais Vol. 2, $\mathrm{N}^{\mathrm{O}}$ 2, Maio-agosto de 2020. Santa Vitória do Palmar - RS.

\subsection{Diretiva sobre a proteção do consumidor em contratos de Timesharing}

Os cinco direitos fundamentais dos consumidores - o direito à proteção da saúde e à segurança, o direito à proteção dos interesses econômicos, o direito a reclamar por danos, o direito à educação e o direito à representação judicial ${ }^{31}$ - orientam a edição e a aplicação das normas de Direito Privado na União Europeia e são, hoje, uma realidade em larga escala.

A pós-modernidade, estágio atual da ciência e da técnica, é o tempo de valorização dos serviços, do lazer, "do abstrato e do transitório", revelando a insuficiência do modelo contratual tradicional do direito civil, o que, nas palavras de Claudia Lima Marques, acaba por "forçar a evolução dos conceitos do direito, a propor uma nova jurisprudência dos valores, uma nova visão dos princípios do direito civil, agora muito mais influenciada pelo direito público e pelo respeito aos direitos fundamentais dos cidadãos." ${ }^{\text {’2 }}$

Nesse contexto, outra relevante Diretiva da União Europeia para a proteção dos consumidores foi aprovada em 2009 e trata da proteção do consumidor relativamente a determinados aspectos dos contratos de utilização periódica de bens, de aquisição de produtos de férias de longa duração, de revenda e de troca. ${ }^{33}$ No contexto do mercado único, transfronteiriço, é imperioso assegurar aos consumidores a harmonização dos seus direitos. A necessidade de tutela acentua-se quando se trata de contratações de longa duração. É justamente esse o caso dos contratos de timesharing.

O contrato de timesharing atribui ao aderente o direito de utilização temporária de bens imóveis, conforme as regras e a disponibilidade ajustadas pelas partes. A contratação do time-sharing não resulta na transferência de propriedade, importa tão somente na cessão temporária e pontual dos direitos de uso de certos bens, geralmente, durante o intervalo das férias - é a consagração "do abstrato e do transitório" a que alude Claudia Lima Marques, antes citada.

A Diretiva 2008/122 ampliou o campo de atuação e atualizou a sua predecessora, a

\footnotetext{
31 WILHELMSSON, Thomas; HOWELLS, Geraint; MICKLITZ, Hans-W. European Consumer Law. In: WERRO, Franz; BUSSANI, Mauro. European Private Law: A handbook. Berne: Stämpfli Publications, 2009. p. 248.

${ }^{32}$ MARQUES, Claudia Lima. Contratos de time-sharing e a proteção dos consumidores: crítica ao direito civil em tempos pós-modernos São Paulo, Revista de Direito do Consumidor, v. 22, p. 64-86, Abr./Jun., 1997.

${ }^{33}$ UNIÃO EUROPEIA. Diretiva 2008/122/CE do Parlamento Europeu e do Conselho de 14 de Janeiro de 2009 sobre a proteção do consumidor relativamente a determinados aspectos dos contratos de utilização periódica de bens, de aquisição de produtos de férias de longa duração, de revenda e de troca. Disponível em: $<$ https://eur-lex.europa.eu/legal-content/PT/TXT/HTML/?uri=CELEX:32008L0122\&from=EN>. Acesso em: 15 out. 2019.
} 
Campos Neutrais - Revista Latino-Americana de Relações Internacionais Vol. 2, $\mathrm{N}^{\mathrm{O}}$ 2, Maio-agosto de 2020. Santa Vitória do Palmar - RS.

Diretiva 94/47/CE do Parlamento Europeu e do Conselho, de 26 de Outubro de 19944, também, relativa à proteção dos adquirentes quanto a certos aspectos dos contratos de aquisição de um direito de utilização a tempo parcial de bens imóveis. A tutela dos consumidores por essa iniciativa contempla desde a formação (contemplando a informação pré-contratual) até a extinção do vínculo contratual. As técnicas habituais de oferta de contratos time-sharing são amplamente criticadas na Europa e no mundo devido às práticas insistentes para a contratação. Assegura-se ao consumidor, inclusive, um prazo durante o qual possa exercer o direito de resolução do contrato sem ter de se justificar e sem suportar qualquer encargo.

Mais recentemente, outras iniciativas da Comissão Europeia visam aperfeiçoar as relações de consumo, fomentando o mercado único para o incremento da segurança dos consumidores na suas contratações. Duas propostas em tramitação merecem especial análise.

\section{Os recentes caminhos para a formação de um mercado único digital}

\subsection{O mercado único digital e a proposta de diretiva sobre certos aspectos dos contratos de vendas online ou à distância de bens}

A expressão escolhida pela Comissão Europeia - Mercado Único Digital - remete à concepção de um mercado no qual é assegurada a livre circulação de mercadorias, de pessoas, de serviços e de capitais e permite que os cidadãos e as empresas possam se beneficiar de um acesso livre a atividades por meio da internet, desenvolvendo-as em condições de concorrência leal e com um elevado nível de proteção dos consumidores, independentemente da sua nacionalidade ou local de residência.

Estima-se que a economia digital possa expandir os mercados e promover de melhores serviços a melhores preços, oferecer uma maior escolha e criar novas fontes de emprego. Objetiva-se que o Mercado Único Digital europeu crie oportunidades para novas empresas em fase de construção e permita que as empresas existentes cresçam e tirem partido da grande escala. ${ }^{35}$

\footnotetext{
${ }^{34}$ UNIÃO EUROPEIA. Diretiva 94/47/CE, do Parlamento Europeu e do Conselho, de 26 de outubro de 1994, relativa à proteção dos adquirentes quanto a certos aspectos dos contratos de aquisição de um direito de utilização a tempo parcial de bens imóveis. Disponível em: <https://eur-lex.europa.eu/legalcontent/PT/TXT/HTML/?uri=CELEX:31994L0047\&from=pt>. Acesso em: 15 out. 2019.

${ }^{35}$ COMISSÃO EUROPEIA. Comunicação da Comissão ao parlamento europeu, ao Conselho, ao Comitê Econômico e social europeu e ao Comitê das Regiões (Estratégia para o Mercado Único Digital na Europa). Disponível 
Campos Neutrais - Revista Latino-Americana de Relações Internacionais Vol. 2, $\mathrm{N}^{\mathrm{O}}$ 2, Maio-agosto de 2020. Santa Vitória do Palmar - RS.

Atualmente, o foco de preocupações da União Europeia, em termos de proteção do consumidor, está voltado para as transações transfronteiriças, especificamente, para as regras relativas aos conteúdos digitais vendidos on-line e as vendas de bens por meio da internet. ${ }^{36}$ Verificou-se, em primeiro lugar, que os consumidores são prejudicados em consequência da ausência de direitos contratuais claros em matéria de conteúdos digitais defeituosos. Além disso, pesquisas empíricas revelaram que os comerciantes poderiam beneficiar-se comercialmente se houvesse um aumento da confiança dos consumidores na realização de compras em outros países da União Europeia. ${ }^{37}$

Em 6 de maio de 2015, foi aprovada pela Comissão Europeia a chamada estratégia do mercado único digital, baseada em três políticas prioritárias: 1) a melhoria do acesso aos bens e aos serviços digitais; 2) o estabelecimento de um ambiente em que as redes e os serviços digitais possam prosperar e 3) a promoção do meio digital como um condutor do crescimento. ${ }^{38}$ Nesse contexto, já foi aprovado pelo Parlamento e pelo Conselho, por exemplo, a proposta de acabar com a cobrança de roaming (deslocamento) nas chamadas telefônicas realizadas em outros países da União Europeia. ${ }^{39}$

A iniciativa de formação de um mercado único digital visa eliminar os principais obstáculos relacionados com o direito dos contratos, que dificultam o comércio transfronteiriço mediante a redução da incerteza com que se deparam as empresas e os consumidores. Tal insegurança é imputada à "complexidade do quadro jurídico e aos custos incorridos pelas empresas decorrentes de diferenças em matéria de direito dos contratos entre Estados-membros." ${ }^{40}$ Em última análise, acredita-se que a concorrência aumentará, conduzindo a um aumento geral do comércio e, consequentemente, a ganhos macroeconômicos para toda a União Europeia.

No entanto, para que os consumidores tivessem confiança no mercado interno e se

content/PT/TXT/HTML/?uri=CELEX:52015DC0192\&from=EN> Acesso em: 15 out. 2019.

${ }^{36}$ DJUROVIC, Mateja. Development of Consumer Law in the European Union. In: Summer School In Consumer Law: National, comparative and international developments. Montreal (Canada), 4 a 9 de julho de 2016.

${ }^{37}$ COMISSÃO EUROPEIA. Proposta de Diretiva do Parlamento Europeu e do Conselho sobre certos aspetos relativos aos contratos de fornecimento de conteúdos digitais. <http://eur-lex.europa.eu/legalcontent/PT/TXT/?uri=CELEX\%3A52015PC0634> Acesso em: 15 out. 2019.

${ }^{38}$ UNIÃO EUROPEIA. Digital Single Market. COM (2015) 192 final. Disponível em: <http://ec.europa.eu/priorities/digital-single-market/> Acesso em: 15 out. 2019.

${ }^{39}$ COMISSÃO EUROPEIA. Comunicado de imprensa. Fim das tarifas de itinerância na UE em 2017: Comissão aprova nova abordagem em benefício de todos os europeus. <http://europa.eu/rapid/pressrelease_IP-16-3111_pt.htm> Acesso em: 15 out. 2019.

${ }^{40}$ COMISSÃO EUROPEIA. Proposta de Diretiva do Parlamento Europeu e do Conselho sobre certos aspetos relativos aos contratos de fornecimento de conteúdos digitais. <http://eur-lex.europa.eu/legalcontent/PT/TXT/?uri=CELEX\%3A52015PC0634> Acesso em: 15 out. 2019. 
Campos Neutrais - Revista Latino-Americana de Relações Internacionais Vol. 2, $\mathrm{N}^{\mathrm{O}}$ 2, Maio-agosto de 2020. Santa Vitória do Palmar - RS.

beneficiassem da sua dimensão, também, no âmbito digital, percebeu-se ser necessário que eles tenham acesso a meios simples, eficazes, céleres e econômicos de resolver eventuais litígios que decorram da compra e venda de bens ou da prestação de serviços on-line -, especialmente, se os consumidores fazem compras além das fronteiras de seus países de domicílio ou de residência.

Ainda em maio de 2013, foi instituído o Regulamento (UE) $\mathrm{n}^{\mathrm{o}} 524 / 2013$, do Parlamento Europeu e do Conselho, para disciplinar a resolução de litígios de consumo online, com a instituição de uma plataforma de resolução de litígios on-line ("plataforma de RLL”). A plataforma facilita a resolução de litígios entre consumidores e comerciantes por meio eletrônico e por via extrajudicial, de forma independente, imparcial, transparente, eficaz, célere e justa. Trata-se de um sítio na internet interativo, gratuito e acessível em todas as línguas oficiais das instituições da União Europeia, o qual centraliza informações e acesso aos centros de resolução extrajudicial de conflitos dos países integrantes da União. ${ }^{41}$

Aplica-se, igualmente, no ambiente digital, o Regulamento (UE) $\mathrm{n}^{\circ} 1215 / 2012$, do Parlamento Europeu e do Conselho, de 12 de dezembro de 2012, relativo à competência judiciária, ao reconhecimento e à execução de decisões em matéria civil e comercial, bem como o Regulamento (CE) n. ${ }^{\circ}$ 593/2008, do Parlamento Europeu e do Conselho, de 17 de junho de 2008, sobre a lei aplicável às obrigações contratuais (Roma I), que estabelecem regras para determinar a jurisdição competente e a lei aplicável. ${ }^{42}$

Avançando nessa perspectiva, em dezembro de 2015, a Comissão Europeia publicou duas propostas de Diretivas para o mercado europeu que assegurariam melhor acesso aos consumidores e aos fornecedores de bens e serviços on-line e simplificariam as regras sobre compras por meio eletrônico. ${ }^{43}$

A primeira proposta de Diretiva apresentada pela Comissão visando à harmonização plena foi a relativa a certos aspectos dos contratos de vendas on-line de bens e outras vendas à distância de bens ("OSG Proposal"44), seguida da diretiva relativa a

\footnotetext{
${ }^{41}$ Com exceção da Croácia, Espanha, Luxemburgo, Polónia, Romênia. (UNIÃO EUROPEIA. Resolução de Litígios em Linha. Disponível em: <https://webgate.ec.europa.eu/odr/main/?event=main.adr.show\#> Acesso em: 15 out. 2019.)

${ }^{42}$ COMISSÃO EUROPEIA. Proposta de Diretiva do Parlamento Europeu e do Conselho sobre certos aspetos relativos aos contratos de fornecimento de conteúdos digitais. <http://eur-lex.europa.eu/legalcontent/PT/TXT/?uri=CELEX\%3A52015PC0634> Acesso em: 15 out. 2019.

${ }^{43}$ MARQUES, Claudia Lima, WEI, Dan (org.) The future of international protection of consumers. Porto Alegre: Programa de Pós-Graduação em Direito, da Universidade Federal do Rio Grande do Sul, 2016. p. 289-290.

${ }^{44}$ COMISSÃO EUROPEIA. Proposta de Diretiva do Parlamento Europeu e do Conselho relativa a certos aspectos que dizem respeito a contratos de vendas em linha de bens e outras vendas de bens à distância.
} 
Campos Neutrais - Revista Latino-Americana de Relações Internacionais Vol. 2, $\mathrm{N}^{\mathrm{O}}$ 2, Maio-agosto de 2020. Santa Vitória do Palmar - RS.

certos aspetos que dizem respeito aos contratos de fornecimento de conteúdos digitais. $\mathrm{Ou}$ seja, a primeira delas sugere requisitos relativos aos contratos de compra e venda à distância celebrados entre o vendedor e o consumidor, especificamente, as regras sobre a conformidade dos bens, os meios de compensação em caso de não conformidade e as modalidades para o exercício desses direitos. Os contratos de prestação de serviços à distância, contudo, estão fora do escopo dessa proposta.

$\mathrm{O}$ artigo $5^{\circ}$ estabelece alguns critérios objetivos para a conformidade dos bens. $\mathrm{Na}$ ausência de cláusulas contratuais explícitas que especifiquem os critérios de conformidade, os bens devem cumprir tais critérios mínimos. $\mathrm{O}$ artigo $7^{\circ}$, no entanto, apresenta um requisito adicional de conformidade relacionado com os vícios jurídicos que os bens possam ter: de acordo com essa regra, os bens devem estar isentos de quaisquer direitos de terceiros, incluindo os baseados na propriedade intelectual.

Caso se verifique uma falta de conformidade do bem entregue ao consumidor em relação ao previsto no contrato, o consumidor terá assegurado o direito de ter os bens repostos pelo vendedor, a título gratuito, através de reparação ou de substituição. A reparação ou substituição deve ser concluída dentro de um prazo razoável e sem inconvenientes significativos para o consumidor, tendo em conta a natureza dos bens e o fim a que se destinam.

O consumidor terá direito, ainda, a reduzir proporcionalmente o preço (em conformidade com o artigo $12^{\circ}$ ) ou a rescindir o contrato (artigo $13^{\circ}$ ) sempre que: $(i)$ a reparação ou substituição for impossível ou ilegal; (ii) o vendedor não tiver concluído a reparação ou a substituição num prazo razoável; (iii) a reparação ou a substituição possa causar inconvenientes significativos para o consumidor; ou ( $i v)$ o vendedor tiver declarado, ou for evidente, a partir das circunstâncias, que não irá repor os bens em conformidade com o contrato, num prazo razoável. Outro ponto interessante da proposta é que o consumidor terá o direito de recusar o pagamento de qualquer parte remanescente do preço até que o vendedor tenha reposto os bens em conformidade com o contrato.

Um levantamento dos custos revelou que o Mercado Único Digital poderia contribuir com, aproximadamente, 415 (quatrocentos e quinze) mil milhões de euros para o produto interno bruto da União Europeia. Isso ocorreria por meio da redução de custos, do aumento do trabalho em mobilidade, de novas oportunidades de negócio e da consolidação de novos mercados. As pessoas que vivem em zonas isoladas e as com um menor poder de

Disponível em: <https://ec.europa.eu/transparency/regdoc/rep/1/2015/PT/1-2015-635-PT-F1-1.PDF> Acesso em: 15 out. 2019. 
Campos Neutrais - Revista Latino-Americana de Relações Internacionais Vol. 2, $\mathrm{N}^{\mathrm{O}}$ 2, Maio-agosto de 2020. Santa Vitória do Palmar - RS.

compra se beneficiam, também, com a consolidação do Mercado Único Digital. ${ }^{45}$

No segundo semestre de 2017, a proposta Diretiva referente a certos aspectos que dizem respeito a contratos de vendas em linha de bens e a outras vendas à distância de bens foi alterada para contemplar, também, as vendas presenciais. Alargou-se, com isso, o âmbito de aplicação da proposta inicial, que se limitava a vendas em linha e a outras vendas à distância. ${ }^{46}$

\subsection{A Proposta de diretiva referente a certos aspectos relativos aos contratos de fornecimento de conteúdos digitais}

A segunda delas é a Proposta de Diretiva do Parlamento Europeu e do Conselho sobre certos aspetos relativos aos contratos de fornecimento de conteúdos digitais ("SDG Proposal'). A justificativa da proposta contempla a preocupação de que, embora alguns Estados-membros, como os Países Baixos, por exemplo, já tenham adotado legislação específica relativa a conteúdos digitais, não existem, atualmente, regras específicas da União com vista à proteção dos consumidores relativa a conteúdos digitais que não estejam em conformidade com o contrato. Logo, é necessário agir rapidamente a fim de evitar uma fragmentação jurídica acrescida, devido ao surgimento de diferentes regras nacionais (possivelmente, divergentes entre si). ${ }^{47}$

A base jurídica da proposta é o artigo $114^{\circ}$, do Tratado sobre o Funcionamento da União Europeia - TFUE (aproximação das disposições legislativas, regulamentares e

\footnotetext{
${ }^{45}$ PARLAMENTO EUROPEU. Communication from the Commission to the European Parliament, the Council, the European Economic and Social Committee and the Committee of the Regions: Unleashing the Potential of Cloud Computing in Europe. Disponível em: <http://www.europarl.europa.eu/atyourservice/pt/displayFtu.html?ftuId=FTU_5.9.4.html> Acesso em: 15 out. 2019.

${ }^{46}$ Confira-se a justificativa das disposições na proposta alterada: "As alterações à proposta inicial são as alterações técnicas necessárias para o alargamento do âmbito de aplicação da proposta e a revogação da Diretiva 1999/44/CE, nomeadamente suprimindo as referências a 'vendas em linha e outras vendas à distância', acrescentando uma disposição relativa à revogação da Diretiva 1999/44/CE, incluindo uma clarificação temporal sobre os contratos que serão abrangidos pelas medidas de execução da proposta alterada e aditando certas disposições da Diretiva 1999/44/CE que são necessárias para a exaustividade da presente diretiva, na sequência da revogação da Diretiva 1999/44/CE, como, por exemplo, a definição de 'produtor'. Por último, foi também introduzida uma série de alterações de natureza técnica para melhorar a coerência e a clareza jurídica do texto." (UNIÃO EUROPEIA. Proposta alterada de Diretiva do Parlamento Europeu e do Conselho relativa a certos aspetos que dizem respeito a contratos de vendas em linha de bens e outras vendas à distância de bens, que altera o Regulamento (CE) n. ${ }^{\circ}$ 2006/2004 do Parlamento Europeu e do Conselho e a Diretiva 2009/22/CE do Parlamento Europeu e do Conselho e que revoga a Diretiva 1999/44/CE do Parlamento Europeu e do Conselho COM/2017/0637 final - 2015/0288 (COD). Disponível em: <https://eur-lex.europa.eu/legal-content/pt/ALL/?uri=CELEX:52017PC0637〉. Acesso em: 15 out. 2019.)

${ }^{47}$ COMISSÃO EUROPEIA. Proposta de Diretiva do Parlamento Europeu e do Conselho sobre certos aspetos relativos aos contratos de fornecimento de conteúdos digitais. <http://eur-lex.europa.eu/legalcontent/PT/TXT/?uri=CELEX\%3A52015PC0634> Acesso em: 15 out. 2019.
} 
Campos Neutrais - Revista Latino-Americana de Relações Internacionais Vol. 2, $\mathrm{N}^{\mathrm{O}}$ 2, Maio-agosto de 2020. Santa Vitória do Palmar - RS.

administrativas dos Estados-membros, que tenham por objeto o estabelecimento e o funcionamento do mercado interno) e o seu principal objetivo é, justamente, a melhoria do estabelecimento e do funcionamento do mercado interno. A definição de conteúdos digitais empregada na proposta $S D G$ é bastante ampla e engloba todos os tipos de conteúdos digitais, tais como, o download ou a difusão de filmes na Internet, o armazenamento em nuvem, as redes sociais e os arquivos-base para impressão em 3D (artigo $2^{\circ}$ da Proposta).

A Diretiva, se aprovada, será aplicável "a qualquer contrato em que o fornecedor fornece ao consumidor conteúdos digitais ou se compromete a fazê-lo e, em contrapartida, é pago um preço ou o consumidor fornece ativamente outra contrapartida que não dinheiro, sob a forma de dados pessoais ou quaisquer outros dados." (artigo $3^{\circ}$ ) Ou seja, estariam sujeitos às regras mesmo os serviços pagos com dados pessoais, salvo se os dados tiverem sido recolhidos, unicamente, para efeitos de cumprimento dos requisitos legais.

Um ponto interessante é o reconhecimento de que o fornecedor seja responsável pela ocorrência de falta de conformidade durante todo o período de uso do bem contratado. Cita-se, exemplificativamente, o armazenamento de arquivos na nuvem. Estipula-se, na proposta, que, dada a frequente melhoria dos conteúdos digitais, nomeadamente, através de atualizações, as versões dos conteúdos digitais fornecidas ao consumidor devem ser as mais recentes disponíveis quando da celebração do contrato.

Sob outro aspecto, nos termos do art. $6^{\circ}$, "sempre que o contrato estabelecer que os conteúdos digitais devem ser fornecidos por um determinado período, os conteúdos digitais devem estar em conformidade com o contrato durante toda a duração desse período." Tal disposição é, especialmente, importante para se evitar a obsolescência programada $^{48}$. Admite-se, todavia, disposição contratual em contrário que estabeleça que os conteúdos digitais devem ser fornecidos em conformidade com a versão mais recente dos disponíveis quando da celebração do contrato.

$\mathrm{O}$ artigo $7^{\circ}$, da Proposta, explica que a falta de conformidade dos conteúdos digitais decorrente de uma integração incorreta nos equipamentos (interligação dos diferentes componentes de um ambiente digital) e de programas informáticos do consumidor deve equivaler a uma falta de conformidade dos próprios conteúdos digitais, isso se os motivos para a incorreta integração se prenderem à esfera do fornecedor.

Considera-se falta de conformidade (advinda do fornecedor), também, a

\footnotetext{
48 Obsolescência programada é de uma estratégia desleal dos fornecedores para estimular a aquisição de novos produtos em um curto período de tempo, objetivando, com isso, alavancar suas vendas e, consequentemente, seu lucro. Tal prática abusiva consiste na redução artificial da durabilidade de produtos ou de seus componentes para que seja forçada a recompra prematura.
} 
Campos Neutrais - Revista Latino-Americana de Relações Internacionais Vol. 2, $\mathrm{N}^{\mathrm{O}}$ 2, Maio-agosto de 2020. Santa Vitória do Palmar - RS.

incompatibilidade do conteúdo digital com os equipamentos e com os programas informáticos do consumidor contratante. Nos termos da proposta, incumbe ao fornecedor o ônus da prova de que os conteúdos digitais se encontram em conformidade com o contrato $\left(\operatorname{artigo} 9^{\circ}\right.$ ). Somente quando o fornecedor prova "que o ambiente digital do consumidor não é compatível com a interoperabilidade e outros requisitos técnicos é que cabe ao consumidor provar que os conteúdos digitais não estão em conformidade com o contrato."

Dessa forma, consoante explicita o artigo $10^{\circ}$, o fornecedor será responsável perante o consumidor, em caso de: i) não fornecimento dos conteúdos digitais; ii) falta de conformidade no momento em que os conteúdos digitais são fornecidos; e iii) sempre que o contrato estabelecer que os conteúdos digitais devem ser fornecidos por um determinado período ou por qualquer falta de conformidade nesse período.

$\mathrm{Na}$ hipótese de rescisão do contrato, o fornecedor deve permitir ao consumidor a recuperação de todos os dados que este carregou, produziu com o uso de conteúdos digitais ou gerou através do uso dos conteúdos digitais. Se um serviço de armazenamento na nuvem é rescindindo ou se outro com melhor custo-benefício é ofertado, o consumidor deve ter facultado o acesso ao conteúdo, ali arquivado, para download.

A proposta Diretiva prevê, ainda, que o consumidor deve ter direito a rescindir qualquer relação contratual que, na sua totalidade, tenha duração superior a um período de 12 (doze) meses. Diz expressamente: "sempre que o contrato estabelecer o fornecimento de conteúdos digitais por tempo indeterminado ou quando a duração inicial do contrato ou qualquer combinação de períodos de renovação exceder 12 meses, o consumidor tem direito a rescindir o contrato em qualquer momento após o termo dos primeiros 12 meses."

Propõe-se, igualmente, a regulamentação do princípio da responsabilidade do fornecedor por danos no contexto da União Europeia para garantir que os consumidores não sejam prejudicados quando o seu equipamento ou os programas informáticos são danificados por conteúdos digitais que não estão em conformidade com o contrato. Mas, nessa hipótese, ficaria a cargo dos Estados-membros o estabelecimento das condições para a reclamação das indenizações correspondentes. Estipula o artigo $14^{\circ}$, com efeito, que "o

fornecedor é responsável perante o consumidor por quaisquer prejuízos econômicos causados ao ambiente digital do consumidor por uma falta de conformidade com o contrato ou pelo não fornecimento dos conteúdos digitais.” As regras propostas conferem maior segurança aos consumidores de conteúdos digitais, explicitando direitos e obrigações mínimas para os contratantes.

Existem, contudo, algumas preocupações em relação às propostas de diretiva em 
Campos Neutrais - Revista Latino-Americana de Relações Internacionais Vol. 2, $\mathrm{N}^{\mathrm{O}}$ 2, Maio-agosto de 2020. Santa Vitória do Palmar - RS.

questão, como um possível maior controle das empresas de telecomunicação sobre a infraestrutura disponível, o que poderia levar ao aumento dos preços aos consumidores; e o whatapp, por exemplo, poderia ser alvo de medidas mais duras de vigilância de conteúdo. ${ }^{49}$

Ainda assim, a proposta não harmonizará todos os aspetos relativos aos contratos de fornecimento de conteúdos digitais. Por exemplo, as regras relativas à celebração dos contratos não serão reguladas. Geralmente, os termos de serviço de fornecedores de conteúdos digitais são alterados unilateralmente, muitas vezes, em detrimento do aderente, mas esse ponto ainda foge do escopo desta proposta.

Um Regulamento, por sua vez, exigiria um regime muito mais pormenorizado e abrangente do que as Diretivas, a fim de permitir que os seus efeitos fossem diretamente aplicáveis. Consequentemente, a interferência, no direito nacional de cada Estado-membro, seria, consideravelmente, maior. Além disso, estima-se que a opção por um regulamento, ao invés das diretivas, poderia "comprometer o caráter duradouro do instrumento, uma vez que, contrariamente a uma diretiva, o nível de pormenor exigido não deixaria margem para adaptar a aplicação das regras plenamente harmonizadas a um mercado comercial e tecnologicamente em constante evolução como o mercado dos conteúdos digitais." 50

\section{Considerações finais}

Entende-se como direito comparado a ciência ou o método que "estuda por meio de contraste, dois ou mais sistemas jurídicos, analisando suas normas positivas, suas fontes, sua história e os variados fatores sociais e políticos que os influenciam." ${ }^{51}$ Revelam-se, por meio desse estudo, as convergências e as divergências.

Nas palavras de Claudia Lima Marques, o direito comparado continua a ter uma função de "autoridade", mas não no sentido de propagar a transposição simples de conceitos e soluções. Na verdade, a resposta está no saber como fazer: "em tempos pósmodernos de hiper-regulamentação e desconstrução, a sabedoria está em verificar como foi feito, no absorver a informação - se possível -, sem pagar... o preço dos erros

\footnotetext{
${ }^{49}$ BERCITO, Diogo. União Europeia divulga propostas para unificar o mercado digital do bloco. Disponível em: <http://www1.folha.uol.com.br/mercado/2016/09/1813260-uniao-europeia-divulga-propostas-paraunificar-o-mercado-digital-do-bloco.shtml> Acesso em: 15 out. 2019.

${ }^{50}$ COMISSÃO EUROPEIA. Proposta de Diretiva do Parlamento Europeu e do Conselho sobre certos aspetos relativos aos contratos de fornecimento de conteúdos digitais. <http://eur-lex.europa.eu/legalcontent/PT/TXT/?uri=CELEX\%3A52015PC0634> Acesso em: 15 out. 2019.

${ }^{51}$ DOLINGER, Jacob.Direito Internacional Privado:parte geral. 6. ed. Rio de Janeiro: Renovar, 2001. p. 43.
} 
Campos Neutrais - Revista Latino-Americana de Relações Internacionais Vol. 2, $\mathrm{N}^{\mathrm{O}}$ 2, Maio-agosto de 2020. Santa Vitória do Palmar - RS.

cometidos." 52

A Estratégia do Mercado Único Digital para a Europa aborda, de forma ampla, os principais obstáculos ao desenvolvimento do comércio eletrônico transfronteiriço na União, buscando garantir um melhor acesso dos consumidores aos conteúdos digitais e facilitar o fornecimento de conteúdos digitais, pelas empresas, para impulsionar a economia digital da União e o crescimento global.

Justifica-se a busca por um Mercado Único Digital para se assegurar, conforme mencionado no início, a livre circulação de mercadorias, de pessoas, de serviços e de capitais, de modo que os cidadãos e as empresas possam acessar e desenvolver as atividades on-line em condições de concorrência leal, com um elevado nível de proteção dos consumidores e dos seus dados pessoais. Acredita-se que a realização de um Mercado Único Digital permitirá à Europa manter uma posição líder na economia digital mundial, ajudando as empresas europeias a crescer globalmente.

Mas, certamente, ainda há um longo caminho a ser percorrido, especialmente, no que concerne à cessão e aos direitos sucessórios sobre esses conteúdos digitais. As propostas diretivas não se aplicam a conteúdos digitais integrados em bens - esses conteúdos funcionam como uma parte integrante, suas funções estão subordinadas às principais funcionalidades dos bens. Também, não são abordados, nas propostas, os direitos de autor e outros aspectos da propriedade intelectual relacionados com o fornecimento de conteúdos digitais. Seria conveniente, outrossim, a consolidação das duas propostas em um único documento.

Mas a despeito de tais considerações, nota-se que é recomendável a incorporação de algumas das regras propostas pelo ordenamento jurídico brasileiro. Em sua obra “Memórias: a construção da Comunidade Europeia”, Jean Monnet deixa a lição de que "a Comunidade que criamos não tem um fim em si mesma [...] é um processo de transformação de continua [...] As nações soberanas do passado não são mais o quadro em que podem resolver os problemas do presente. E a própria Comunidade é apenas uma etapa em direção às formas de organização do mundo de amanhã." 53

\footnotetext{
${ }^{52}$ MARQUES, Claudia Lima. Normas de proteção do consumidor (especialmente, no comércio eletrônico) oriundas da União Europeia, e o exemplo de sua sistematização no código civil alemão de 1896 - notícia sobre as profundas modificações no bgb para incluir a figura do consumidor. São Paulo, Revista de Direito Privado, v. 4, Out./Dez., 2000. p. 50-93.

${ }^{53}$ MONNET, Jean. Memórias: a construção da Comunidade Europeia. Tradução: Ana Maria Falcão. Brasília: Editora Universidade de Brasília, 1986. p. 460-461.
} 
Campos Neutrais - Revista Latino-Americana de Relações Internacionais Vol. 2, $\mathrm{N}^{\mathrm{O}}$ 2, Maio-agosto de 2020. Santa Vitória do Palmar - RS.

\section{Referências}

BENJAMIN, Antonio Herman; MARQUES, Claudia Lima. Extrato do Relatório-Geral da Comissão de Juristas do Senado Federal para atualização do Código de Defesa do Consumidor (14.03.2012). São Paulo, Revista de Direito do Consumidor, v. 92, Mar./Abr., 2014.

BERCITO, Diogo. União Europeia divulga propostas para unificar o mercado digital do bloco. Disponível em: <http://www1.folha.uol.com.br/mercado/2016/09/1813260-uniao-europeiadivulga-propostas-para-unificar-o-mercado-digital-do-bloco.shtml> Acesso em: 15out. 2019.

COMISSÃO EUROPEIA. Comunicação da Comissão ao parlamento europeu, ao Conselho, ao Comitê Econômico e social europeu e ao Comitê das Regiões (Estratégia para o Mercado Único Digital na Europa). Disponível em: <http://eur-lex.europa.eu/legalcontent/PT/TXT/HTML/?uri=CELEX:52015DC0192\&from=EN>Acesso em:15out. 2019.

COMISSÃO EUROPEIA. Comunicado de imprensa. Fim das tarifas de itinerância na UE em 2017: Comissão aprova nova abordagem em benefício de todos os europeus.

<http://europa.eu/rapid/press-release_IP-16-3111_pt.htm> Acesso em: 15out. 2019.

COMISSÃO EUROPEIA. Proposta de Diretiva do Parlamento Europeu e do Conselho relativa a certos aspectos que dizem respeito a contratos de vendas em linha de bens e outras vendas à distância de bens. Disponível em: <https://ec.europa.eu/transparency/regdoc/rep/1/2015/PT/12015-635-PT-F1-1.PDF> Acesso em: 15out. 2019.

COMISSÃO EUROPEIA. Proposta de Diretiva do Parlamento Europeu e do Conselho sobre certos aspetos relativos aos contratos de fornecimento de conteúdos digitais. <http://eurlex.europa.eu/legal-content/PT/TXT/?uri=CELEX\%3A52015PC0634> Acesso em: 15out. 2019.

DOLINGER, Jacob.Direito Internacional Privado:parte geral. 6. ed. Rio de Janeiro: Renovar, 2001.

DURÁ, Rafael Marimón. La protección de los consumidores en el derecho comunitario europeo. In:PIMENTEL, Luiz Otávio; MOTA, Carlos Esplugues; BARRAL, Welber. Direito Internacional Privado: União Europeia e Mercosul. Florianópolis: Fundação Boiteux, 2007.

DJUROVIC, Mateja.The Apple Case Today: Factual and Legal Assessment. Disponível em: <http://papers.ssrn.com/sol3/papers.cfm?abstract_id=2736380> Acesso em: 15out. 2019.

JAEGER JUNIOR, Augusto. Mercados Comum e Interno e Liberdades Econômicas Fundamentais. Curitiba: Juruá Editora, 2010.

MANSEL, Heinz-Peter; PFEIFFER, Thomas; KRONKE, Herbert; KRONKE, Christian; HAUSMANN, Rainer(org.)Festschrift für Erik Jayme. Band I. Munique: GmbH Publishers, 2004.

MARQUES, Claudia Lima. Contratos de time-sharing e a proteção dos consumidores: crítica ao direito civil em tempos pós-modernos São Paulo, Revista de Direito do Consumidor, v. 22, p. 6486, Abr./Jun., 1997.

;WEI, Dan (org.) The future of international protection of consumers. Porto Alegre: Programa de Pós-Graduação em Direito da Universidade Federal do Rio Grande do Sul, 2016.

MIRAGEM, Bruno. A defesa administrativa do consumidor no Brasil. São Paulo, Revista de Direito do Consumidor, v. 46, Abr./Jun., 2003.

MONNET, Jean. Memórias: a construção da unidade europeia(1976). Tradução: Ana Maria Falcão. Brasília: Editora Universidade de Brasília, 1986.

MOSCONI, Franco. Diritto internazionale privato uniforme e disposizioni generali di diritto internazionale privato nazionale. In: MANSEL, Heinz-Peter; PFEIFFER, Thomas; KRONKE, Herbert; Kronke, Christian; HaUSMAnN, Rainer(org.) Festschrift für Erik Jayme. Band I. Munique: GmbH Publishers, 2004.

PARLAMENTO EUROPEU. Communication from the Commission to the European Parliament, 
Campos Neutrais - Revista Latino-Americana de Relações Internacionais Vol. 2, $\mathrm{N}^{\mathrm{O}}$ 2, Maio-agosto de 2020. Santa Vitória do Palmar - RS.

the Council, the European Economic and Social Committee and the Committee of the Regions: Unleashing the Potential of Cloud Computing in Europe. Disponível em:

<http://www.europarl.europa.eu/atyourservice/pt/displayFtu.html?ftuId=FTU_5.9.4.html> Acesso em: 15out. 2019.

PIMENTEL, Luiz Otávio; MOTA, Carlos Esplugues; BARRAL, Welber. Direito Internacional Privado: União Europeia e Mercosul. Florianópolis: Fundação Boiteux, 2007.

RECHSTEINER, Beat Walter. Direito Internacional Privado:teoria e prática. 12. ed. São Paulo: Saraiva, 2009.

UNIÃO EUROPEIA. A União Europeia por temas: consumidores. Disponível em: <https://europa.eu/european-union/topics/consumers_pt> Acesso em: 15out. 2019.

UNIÃO EUROPEIA. Carta dos Direitos Fundamentais da União Europeia. Disponível em: $<$ https://europa.eu/european-union/sites/europaeu/files/eu_citizenship/consolidated-

treaties_pt.pdf\#page=125> Acesso em: 15 out. 2019.

UNIÃO EUROPEIA. Digital Single Market(COM (2015) 192 final). Disponível em: <http://ec.europa.eu/priorities/digital-single-market/> Acesso em: 15out. 2019.

UNIÃO EUROPEIA. Diretiva 93/13/CEE do Conselho, de 5 de abril de 1993, relativa às cláusulas abusivas nos contratos celebrados com os consumidores. Disponível em: <http://eurlex.europa.eu/legal-content/PT/TXT/HTML/?uri=CELEX:31993L0013\&from=en> Acesso em: 15out. 2019.

UNIÃO EUROPEIA. Diretiva 1995/46/CE do Parlamento Europeu e do Conselho. Disponível em: $<$ http://eur-lex.europa.eu/legal-content/pt/TXT/?uri=CELEX\%3A31995L0046> Acesso em: 15out. 2019.

UNIÃO EUROPEIA. Diretiva 1999/44/CE do Parlamento Europeu e do Conselho, de 25 de maio de 1999, relativa a certos aspectos da venda de bens de consumo e das garantias a ela relativas. Disponível em: $<\mathrm{http} / / /$ eur-lex.europa.eu/legalcontent/PT/TXT/HTML/?uri=CELEX:31999L0044\&from=GA> Acesso em: 15out. 2019.

UNIÃO EUROPEIA. Diretiva 2002/58/CE do Parlamento Europeu e do Conselho, de 12 de julho de 2002, relativa ao tratamento de dados pessoais e à proteção da privacidade no setor das comunicações eletrônicas. Disponível em: <http://eur-lex.europa.eu/legalcontent/PT/TXT/HTML/?uri=URISERV:124120\&from=PT> Acesso em: 15out. 2019.

UNIÃO EUROPEIA. Diretiva 2005/29/CE do Parlamento Europeu e do Conselho, de 11 de maio de 2005, relativa às práticas comerciais desleais das empresas face aos consumidores no mercado interno. $<$ http://eur-lex.europa.eu/legalcontent/PT/TXT/HTML/?uri=CELEX:32005L0029\&from=EM> Acesso em: 15out. 2019.

UNIÃO EUROPEIA. Diretiva 2008/122/CE do Parlamento Europeu e do Conselho de 14 de Janeiro de 2009 sobre a proteção do consumidor relativamente a determinados aspectos dos contratos de utilização periódica de bens, de aquisição de produtos de férias de longa duração, de revenda e de troca. Disponível em: <https://eur-lex.europa.eu/legalcontent/PT/TXT/HTML/?uri=CELEX:32008L0122\&from=EN>. Acesso em: 15 out. 2019.

UNIÃO EUROPEIA. Diretiva 2009/22/CE do Parlamento Europeu e do Conselho, de 23 de abril de 2009, relativa às ações inibitórias em matéria de proteção dos interesses dos consumidores. Disponível em: <http://eur-lex.europa.eu/legalcontent/PT/TXT/HTML/?uri=CELEX:32009L0022\&from=EN > Acesso em: 15out. 2019.

UNIÃO EUROPEIA. Diretiva 2011/83/UE do Parlamento Europeu e do Conselho, de 25 de outubro de 2011, relativa aos direitos dos consumidores. Disponível em: <http://eurlex.europa.eu/legal-content/PT/TXT/HTML/?uri=CELEX:32011L0083\&from=GA> Acesso em: 15out. 2019.

UNIÃO EUROPEIA. Diretiva 2013/11/UE do Parlamento Europeu e do Conselho, de 21 de maio 
Campos Neutrais - Revista Latino-Americana de Relações Internacionais Vol. 2, $\mathrm{N}^{\mathrm{O}}$ 2, Maio-agosto de 2020. Santa Vitória do Palmar - RS.

de 2013, sobre a resolução alternativa de litígios de consumo. Disponível em: <http://eurlex.europa.eu/legal-content/PT/TXT/HTML/?uri=CELEX:32013L0011\&from=em> Acesso em: 15out. 2019.

UNIÃO EUROPEIA. Proposta de Regulamento do Parlamento Europeu e do Conselho relativo a um direito europeu comum da compra e venda (COM/2011/0635 final - 2011/0284 - COD). Disponível em: <http://eur-lex.europa.eu/legalcontent/PT/TXT/HTML/?uri=CELEX:52011PC0635\&from=EN> Acesso em: 15out. 2019.

UNIÃO EUROPEIA. Proposta alterada de Diretiva do Parlamento Europeu e do Conselho relativa a certos aspetos que dizem respeito a contratos de vendas em linha de bens e outras vendas à distância de bens, que altera o Regulamento (CE) n. ${ }^{\circ}$ 2006/2004 do Parlamento Europeu e do Conselho e a Diretiva 2009/22/CE do Parlamento Europeu e do Conselho e que revoga a Diretiva 1999/44/CE do Parlamento Europeu e do Conselho COM/2017/0637 final - 2015/0288 (COD). Disponível em: <https://eur-lex.europa.eu/legal-content/pt/ALL/?uri=CELEX:52017PC0637>. Acesso em: 15 out. 2019.

UNIÃO EUROPEIA. Regulamento (UE) n ${ }^{\circ}$ 254/2014 do Parlamento Europeu e do Conselho, de 26 de fevereiro de 2014, relativo a um programa plurianual "consumidores" para o período 2014-2020 e que revoga a Decisão $\mathrm{n}^{\circ}$ 1926/2006/CE. <http://eur-lex.europa.eu/legalcontent/PT/TXT/HTML/?uri=CELEX:32014R0254\&from=PT> Acesso em: 15out. 2019.

UNIÃO EUROPEIA. Regulamento (UE) n ${ }^{\circ}$ 2006/2004 do Parlamento Europeu e do Conselho, de 27 de outubro de 2004, relativo à cooperação entre as autoridades nacionais responsáveis pela aplicação da legislação de defesa do consumidor. <http://eur-lex.europa.eu/legalcontent/PT/TXT/HTML/?uri=URISERV:132047\&from=EN> Acesso em: 15out. 2019.

UNIÃO EUROPEIA. Resolução de Litígios em Linha (online). Disponível em: $<$ https://webgate.ec.europa.eu/odr/main/?event=main.adr.show\#> Acesso em: 15out. 2019.

UNIÃO EUROPEIA. Tratado da União Europeia (Maastricht, 1992). Disponível em: $<$ https://europa.eu/europeanunion/sites/europaeu/files/docs/body/treaty_on_european_union_pt.pdf> Acesso em: 15out. 2019.

UNIÃO EUROPEIA. Tratado de Amsterdam (outubro de 1997). Disponível em: <https://europa.eu/european-union/sites/europaeu/files/docs/body/treaty_of_amsterdam_pt.pdf> Acesso em: 15out. 2019.

UNIÃO EUROPEIA. Tratado sobre o Funcionamento da União Europeia - TFUE. Disponível em: $<$ https://europa.eu/european-union/sites/europaeu/files/eu_citizenship/consolidatedtreaties_pt.pdf\#page=125> Acesso em: 15 out. 2019.

VIEIRA, Luciane Klein. Protección Internacional del Consumidor: procesos de escasa cuantía en los titigios transfronteirizos. Buenos Aires: Editorial B de F, 2013.

VON BAR, Christian; CLIVE, Eric; SCHULTE-NÖLKE, Hans. Principles, Definitions and Model Rules of European Private Law Draft Common Frame of Reference (DCFR). Disponível em: $<$ http://ec.europa.eu/justice/policies/civil/docs/dcfr_outline_edition_en.pdf $>$ Acesso em: 15out. 2019. 